\title{
Efficiency comparison between the LLCL- and LCL-filters based single-phase grid-tied inverters
}

\author{
Weimin Wu ${ }^{1}$, Min HuAng ${ }^{1,2}$, FRede BlaAbJERG ${ }^{2}$ \\ ${ }^{1}$ Department of Electrical and Electronic Engineering, Shanghai Maritime University, Shanghai, China \\ e-mail:wmwu@shmtu.edu.cn,hmi@et.aau.dk \\ ${ }^{2}$ Department of Energy Technology, Aalborg University, Aalborg, Demark \\ e-mail:fbl@et.aau.dk
}

(Received: 18.10.2013, revised: 07.01.2014)

\begin{abstract}
An LLCL-filter is becoming more attractive than an LCL-filter as the interface between the grid-tied inverter and the grid due to possibility of reducing the copper and the magnetic materials. The efficiency of the LLCL-filter based single-phase grid-tied inverter also excites interests for many applications. The operation of the switches of the VSI is various with different modulation methods, which lead to different efficiencies for such a single-phase grid-tied inverter system, and therefore important research has been carried out on the effect of the choice of PWM schemes. Then power losses and efficiencies of the LLCL-filter and the LCL-filter based single-phase grid-tied inverters are analyzed and compared under the discontinuous unipolar, the dual-buck and the bipolar modulations. Results show that the efficiency of LLCL-filter based inverter system is higher than the LCL- filter based independent on the modulation method adopted. Experiments on a $2 \mathrm{~kW}$ prototype are in good agreement with results of the theoretical analysis.
\end{abstract}

Key words: LCL-filter, LLCL-filter, efficiency power loss, modulation, single-phase grid-tied inverter

\section{Introduction}

Due to the energy crisis, renewable energy resources are becoming interesting and the grid-tied Voltage Source Inverter (VSI), which interconnects between renewable energy such as solar energy, wind energy, etc and the power grid, has been widely applied [1]. Normally, the VSI adopts Sinusoidal Pulse Width Modulation (SPWM) to maintain that the Total Harmonic Distortion (THD) of the input current is below 5\%. In order to limit the excessive current harmonics injected in the point of common coupling, a low-pass power filter is inserted between the voltage source inverter (VSI) and the grid $[2,3]$.

Traditionally, an LCL- filter is attractive for the grid-tied VSI application due to the lower inductance, compared to an L-filter. Recently, a new high-order filter called LLCL-filter was 
proposed [4]-[7]. Compared to the conventional LCL-filter, it inserts a small inductor in the branch loop of the capacitor composing an $\mathrm{L}_{\mathrm{f}} \mathrm{C}_{\mathrm{f}}$ series resonant circuit tuned at the switching frequency, which can meet the harmonic current recommendations of IEEE 519-1992 with smaller inductance or capacitance. The topology is shown in Figure 1.

The efficiency of the grid-tied VSI is also an issue that attracts the attentions of many researchers [8,9], especially in PV generation systems. The operation of the switches of the VSI is various with different modulation methods, which lead to different efficiencies for such an inverter system. In the past decades, several SPWM techniques has been proposed and developed to achieve the proper voltage and frequency control. Important research have has been carried out on the effect of the choice of PWM schemes [10-13].

This paper aims to compare the overall efficiency between LLCL- filter and LCL- filter based single-phase grid-tied inverters. The efficiency comparison of the inverters is carried out using the discontinuous unipolar modulation, the dual-buck modulation $[12,13]$ and the bipolar modulation. In order to depict the switching action for calculating the power losses, three typical modulations are introduced first. Then, power losses of inverter power components are analyzed under these modulations. Next, the power loss calculation results of the LLCL-filter and the LCL-filter are given, and continued with the full calculated efficiency comparison. Finally, experimental results on a $2 \mathrm{~kW}$ prototype are carried out and compared with the theoretical analysis.

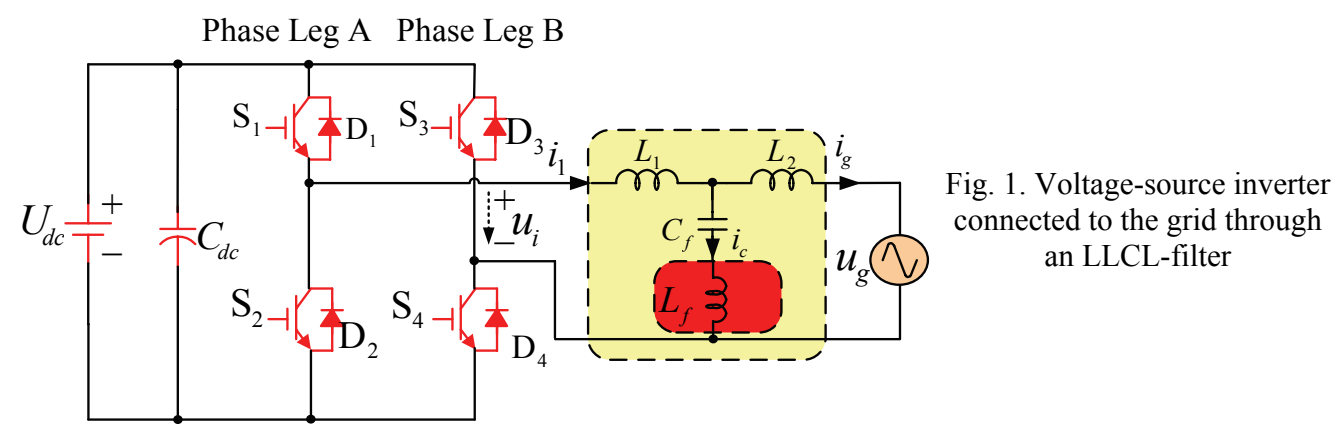

\section{Modulations for single-phase grid-tied inverter}

According to the level of the output voltage of the inverter, the modulations of a singlephase inverter are mainly classified into two categories: three-level modulation and two-level modulation, which also are called unipolar modulation and bipolar modulation respectively [14].

\section{A. Unipolar modulation}

Based on the switching sequence during the fundamental cycle, the unipolar modulation can be divided into two types: the continuous unipolar modulation and the discontinuous unipolar modulation. 
1) Continuous unipolar modulation

For the continuous unipolar modulation, each phase leg of the inverter switches between the upper and the lower DC-rails continuously over the fundamental cycle as the carrier waveform ramps above and below reference waveform. Figure 2 shows the reference waveform, the carrier and driving signals of the inverter under the continuous unipolar modulation, where $v_{\mathrm{s} 1}, v_{\mathrm{s} 2}, v_{\mathrm{s} 3}$ and $v_{\mathrm{s} 4}$ are the driving signals for corresponding switches as shown in Figure land the driving signals of the same phase leg are complementary. The switching frequency of the current of the inverter-side inductor is twice the carrier frequency, due to the interaction between the phase-leg transitions. The size and volume of the filter inductors and capacitors can thereby be reduced.

Fig. 2. Voltage reference, carrier and driving signals under the continuous unipolar modulation

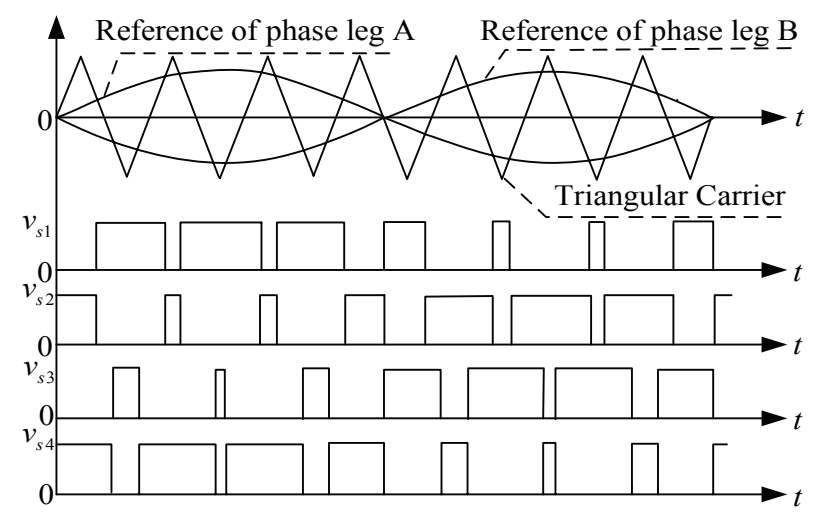

2) Discontinuous unipolar modulation

Similarly, the discontinuous unipolar modulation also can be divided into two categories as shown in Figure 3. Figure 3a) depicts a cost-effective approach where only phase leg B is modulated and phase leg A switches between negative DC-rail and positive DC-rail for each half fundamental cycle. The other discontinuous unipolar modulation method presented in Figure 3b) requires both phase legs to be modulated and demands a certain level of complexity for the controller implementation, where only phase leg B is modulation in the first half of the fundamental cycle and phase leg A is modulated during the second half of the fundamental cycle. The phase legs never switch together within one carrier period under this modulation. Compared with the continuous modulation, the output pulses of inverter occur only at the carrier frequency since only one phase leg chops at high frequency during a half of the fundamental cycle.

\section{B. Dual-buck modulation}

The dual-buck modulation is similar to the discontinuous unipolar modulation, but the difference is that only one switch of each phase leg is modulated and the other switch is off. In this case, the inverter works like a pure buck converter. Thereby, the current through the inverter-side inductor cannot be reversed during each carrier period. 
a)

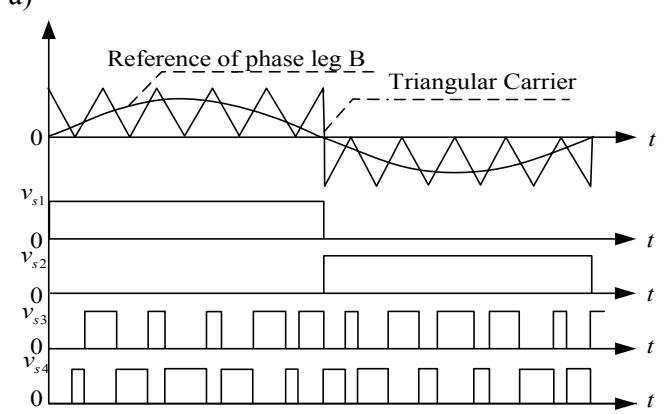

b)

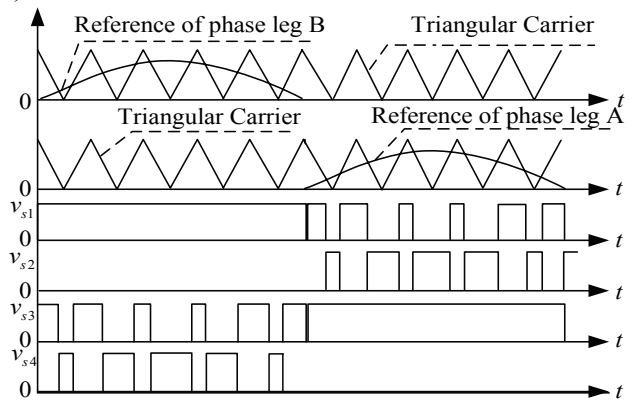

Fig. 3. Voltage reference, carrier and driving signals under the discontinuous unipolar modulation: a) single phase leg B is modulated, b) both phase legs are modulated

\section{Bipolar modulation}

The output voltage of the single-phase inverter produced by bipolar modulation is quite different compared to the unipolar modulation, since it continuously switches between positive and negative pulses during each carrier period without any zero states. As shown in Figure 4, the bipolar modulation can be implemented with very simple circuitry since one phase leg maintains the inverse switch state of the other.

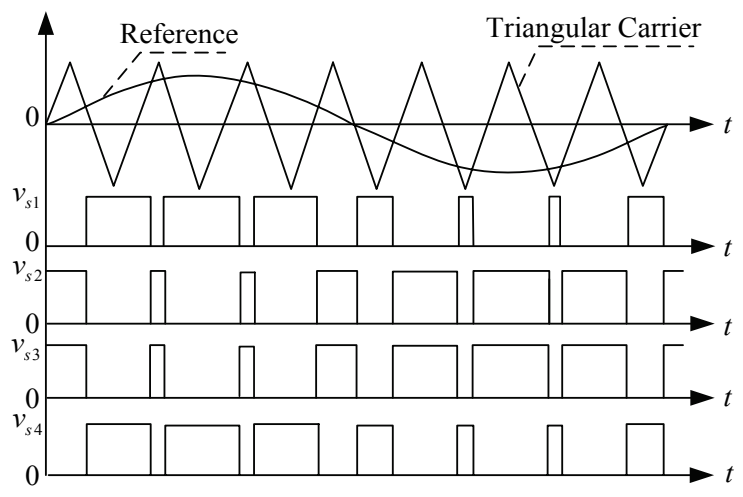

Fig. 4. Voltage reference, carrier and driving signals under the bipolar modulation

The effects of the continuous unipolar modulation and the discontinuous unipolar modulation are similar except for the equivalent switching frequency, so in the following efficiency comparison between the LLCL-filter and the LCL-filter based single-phase grid-tied inverters will be carried out only with the discontinuous unipolar modulation, the dual-buck modulation and the bipolar modulation. 


\section{Analysis on power losses of components}

The design procedures of LLCL-filter and LCL-filter are described in [4] and [15]. In this paper, the choice of parameters is based on the principle that the current ripple ratio (which is selected as 30\%) and the harmonic current attenuation of the LLCL-filter and the LCL-filter are the same. The current ripple ratio can be calculated as

$$
\xi=\frac{\Delta I_{1}}{I_{\text {ref }}}=\frac{k U_{d c}}{4 L_{1} f_{s} I_{\text {ref }}},
$$

where $U_{\mathrm{dc}}$ is the input DC voltage of inverter, $L_{1}$ is the inverter-side inductor, $f_{\mathrm{s}}$ is the switching frequency, $I_{\text {ref }}$ is the RMS given current, and $k$ is constant which depends on the modulation mode (for the unipolar modulation and the dual-buck modulation, $k=1$, And for the bipolar modulation, $k=2$ ). The inductance of the inverter-side inductor $L_{1}$ under the bipolar modulation method is twice that under the unipolar modulation method and the dualbuck modulation. The designed parameters of the filters are listed in Table 1.

Table 1. Filter parameter values used in design

\begin{tabular}{c|c|c|c|c}
\hline $\begin{array}{c}\text { Modulation } \\
\text { method }\end{array}$ & $\begin{array}{c}\text { Discontinuous unipolar modulation } \\
\text { / dual-buck modulation }\end{array}$ & \multicolumn{2}{c}{ Bipolar modulation } \\
\hline Parameter & LCL-filter & LLCL-filter & LCL-filter & LLCL-filter \\
\hline$L_{1}$ & $1.2 \mathrm{mH}$ & $1.2 \mathrm{mH}$ & $2.4 \mathrm{mH}$ & $2.4 \mathrm{mH}$ \\
\hline$L_{2}$ & $1.2 \mathrm{mH}$ & $0.22 \mathrm{mH}$ & $1.6 \mathrm{mH}$ & $0.22 \mathrm{mH}$ \\
\hline$L_{\mathrm{f}}$ & - & $32 \mu \mathrm{H}$ & - & $32 \mu \mathrm{H}$ \\
\hline$C_{\mathrm{f}}$ & $2 \mu \mathrm{F}$ & $2 \mu \mathrm{F}$ & $2 \mu \mathrm{F}$ & $2 \mu \mathrm{F}$ \\
\hline
\end{tabular}

The inverter-side inductor $L_{1}$ of the LLCL-filter is the same as that of the LCL-filter. Since the grid currents are nearly sinusoidal, the power losses of the power components of both the LLCL- and the LCL-filter based inverter are the same, only if using the same modulation strategy. In this paper, the power loss analysis is based on a $2 \mathrm{~kW}$ grid-tied inverter prototype using the IGBT module of SK30GBB066T under the conditions that are listed in Table 2.

Table 2. Converter ratings used for calculations of filter losses

\begin{tabular}{c|c|c|c|c|c|c|c}
\hline $\boldsymbol{U}_{\mathbf{d c}}$ & $\boldsymbol{P}_{\mathbf{o}}$ & $\boldsymbol{f}_{\boldsymbol{o}}$ & $\boldsymbol{f}_{\mathrm{s}}$ & $\boldsymbol{\alpha}$ & $\boldsymbol{U}_{\mathbf{g}}$ & $\boldsymbol{C}_{\mathbf{f}}$ & $\boldsymbol{\delta}$ \\
\hline $\mathrm{V}$ & $\mathrm{W}$ & $\mathrm{Hz}$ & $\mathrm{kHz}$ & 1 & $\mathrm{~V}$ & $\mathrm{pu}$ & \\
\hline 350 & 2000 & 50 & 20 & 0.899 & 220 & 0.015 & $0.15 \%$ \\
\hline
\end{tabular}

where $p_{\mathrm{o}}$ is generated power, $f_{\mathrm{o}}$ is the line frequency of the grid voltage, $\alpha$ is the modulation index, $U_{\mathrm{g}}$ is the RMS grid voltage and $\delta$ is the designed harmonic current attenuation of higher than the $35^{\text {th }}$ harmonics. 
The power losses of the power components can be classified into the conduction loss, the turn-on power loss, the turn-off power loss and the off-state blocking loss, where the blocking loss is generally small and can typically be neglected $[16,17]$. In this paper, the power loss calculation is based on the curve-fitting method with the parameters and characteristic curves of the IGBT provided by the manufacturer.

Before calculating the power loss of the inverter, some assumptions are done:

a) Leakage inductance and other parasitic parameters are not included in the loss calculations,

b) The $\mathrm{DC}$ voltage ripple and fluctuations are neglected,

c) The junction temperature is assumed constant at $75^{\circ} \mathrm{C}$ in the devices,

d) The turn-on loss of diode is small enough to be neglected,

e) Dead-time and delays are not considered.

\section{A. Discontinuous unipolar modulation}

When the discontinuous unipolar modulation is adopted, the duty cycle of the inverter, $D(\theta)$, can be described as:

$$
D(\theta)=\frac{U_{g} \sin (\theta)}{U_{d c}},
$$

where

$$
\theta=\frac{2 \pi f_{o}}{f_{s}}, \frac{4 \pi f_{o}}{f_{s}}, \ldots, \pi
$$

and due to the symmetry of the circuit, $\theta$ ranges from $0-\pi$ during the positive output voltage period.

It is assumed that the fundamental component of the current of the inverter-side inductor, $i_{1}$, is in phase with the fundamental component of the output voltage of the inverter, $u_{\mathrm{i}}$. As shown in Figure 1, during the positive period of $U_{\mathrm{i}}$, the expected current of $i_{1}$, flows through $S_{1}$ and $S_{4}$ when $S_{4}$ is on, and freewheels through $D_{3}$ and $S_{1}$ while $S_{4}$ is off. Since the discontinuous unipolar modulation method is applied, the inductor will discharge quickly and the real current of $i_{1}$ may be reversed through $D_{1}$ and $S_{3}$ under the effect of grid voltage when the inverter-side inductance is small. If the reversal of $i_{1}$ has taken place, when turn off $S_{3}$ and turn on $S_{4}, i_{1}$ will freewheel through $D_{1}$ and $D_{4}$ until the current reaches zero.

1) Conduction power losses of IGBTs and free-wheeling diodes

The conduction loss is calculated as the product of the device current and the forward saturation voltage. The forward saturation voltagev $\left(i, T_{C}\right)$ changes with the current, the gate-driven voltage and the junction temperature $\left(T_{C}\right)$. In this paper, the voltage characteristic is fitted under the condition that the gate-emitter voltage is $15 \mathrm{~V}$ and the junction temperature is $75^{\circ} \mathrm{C}$. Taken the calculation of $S_{1}$ as an example, the formula of the conduction loss of $S_{1}$ can be deduced as follows,

$$
P_{S_{1_{-} \text {onsatale }}}=\frac{1}{T} \sum_{\theta} \int_{0}^{D(\theta) T_{S}} v_{C E_{-} I G B T}\left(i_{S_{1_{-} \text {onstate }}, 75}\right) . i_{S_{1_{-} \text {onstatel }}} d t,
$$




$$
P_{S_{1} \text { onstate } 2}=\frac{1}{T} \sum_{\theta} \int_{0}^{(1-D(\theta)) T_{s}} v_{C E_{-} I G B T}\left(i_{S_{1_{1} \text { onstata } 2}}, 75\right) \cdot i_{S_{1_{-} \text {onstate } 2}} d t
$$

where $T_{s}$ is the switching period, $T$ is the grid fundamental frequency period; $P_{S_{1} \text { onstatel }}$ is the conduction loss of $S_{1}, i_{S_{1} \text { onstate }}$ is the current of $S_{1}$, when the $S_{4}$ is on; $P_{S_{1} \text { onstate }}$ is the conduction loss of $S_{1}, i_{S_{1} \text { onstate } 2}$ is the current of $S_{1}$, when the $S_{4}$ is off. The conduction loss calculation of other IGBTs and diodes is similar to the calculation of $S_{1}$.

2) Power losses caused by turn-on of IGBT $S_{4}$

When $S_{4}$ turns on, $D_{3}$ changes from conductive state to blocking state, if the current of $i_{1}$ is positive. The total power loss during switching-on of $S_{4}$ is divided into three main parts, including the power loss during the current rise from $10 \%$ to $90 \%$ of the load current, the power loss caused by the reverse recovery change of $D_{3}$ and the residual part $[18,19]$. According to the turn-on loss curve of the IGBT, $E_{S_{-} \text {on }}(i)$, the turn-on loss of $S_{4}$ can be calculated as follows,

$$
P_{S_{4_{-} \text {on }}}=\frac{1}{T} \sum_{\theta} E_{S_{-} \text {on }}\left(i_{S_{4_{-} \text {on }}}\right),
$$

where $i_{S_{4}}$ on is the current of $S_{4}$ at each turn-on instant. Similarly, according to the turn-off loss curve of $D_{3}$ caused by reverse recovery, $E_{D_{-} \text {off }}(i)$, the turn-off loss of $D_{3}$ can be calculated as follows,

$$
P_{D_{3_{-} \text {off }}}=\frac{1}{T} \sum_{\theta} E_{D_{-} \text {off }}\left(i_{D_{3_{-} \text {off }}}\right),
$$

3) Turn-off losses of IGBT $S_{4}$ and $S_{3}$ According to turn-off loss curve of $S_{4}, E_{S_{-} \text {off }}(i)$, the turn-off loss of $\mathrm{S}_{4}$ can be calculated as,

$$
P_{S_{4_{-} \text {off }}}=\frac{1}{T} \sum_{\theta} E_{S_{-} \text {off }}\left(i_{S_{S_{-} \text {off }}}\right),
$$

where $i_{S_{4} \text { off }}$ is the current of $S_{4}$ at each turn-off instant. It should be pointed out that when the output voltage of the inverter is positive and the current of $i_{1}$ is negative, switching off $S_{3}$ will cause turn-off power loss. The turn-off power loss can be deduced similarly.

\section{B. Dual-buck modulation}

The calculation of the power losses in the power components under the dual-buck modulation is similar to the calculation of the discontinuous unipolar modulation. The difference is that the power losses caused by the reverse current do not exist. For example, during the positive line frequency cycle, no power losses are being with $S_{3}, D_{1}$ and $D_{4}$. This advantage of the dual-buck mode is highlighted in the case of a large current ripple when $L_{1}$ is small.

\section{Bipolar modulation}

Compared with the unipolar modulation, the bipolar modulation can suppress common mode interference well. But this modulation method will lead to extra switching losses be- 
cause four switches are operating at the high frequency at the same time. The duty cycle of the inverter, $D^{\prime}(\theta)$, can be described as:

$$
D^{\prime}(\theta)=\frac{U_{d c}+U_{g} \sin (\theta)}{2 U_{d c}} .
$$

As shown in Figure1, during the positive line frequency cycle, the expected current of $i_{1}$, flows through $S_{1}$ and $S_{4}$ when $S_{1}$ and $S_{4}$ are on, and freewheels through $D_{2}$ and $D_{3}$ while $S_{2}$ and $S_{3}$ are on. When the inverter-side inductance is small, the inductor will discharge quickly and the real current $i_{1}$ reverses through $S_{2}$ and $S_{3}$ under the influence of the grid voltage. The power loss calculation method of the bipolar modulation is similar to that of the discontinuous unipolar modulation.

\section{Results of the calculated power component power losses under the three modulation methods}

According to parameters and conditions listed in the Table 1 and Table 2, the power losses of the inverter power components under the three modulation methods are shown in Figure 5. It can be seen that the power losses under bipolar modulation are much higher than using unipolar modulation and dual buck modulation due to the higher switching power losses. The power losses under discontinuous unipolar modulation and dual-buck modulation are nearly the same when the current ripple ratio is $30 \%$ and only a small difference can be observed, when output power is low.

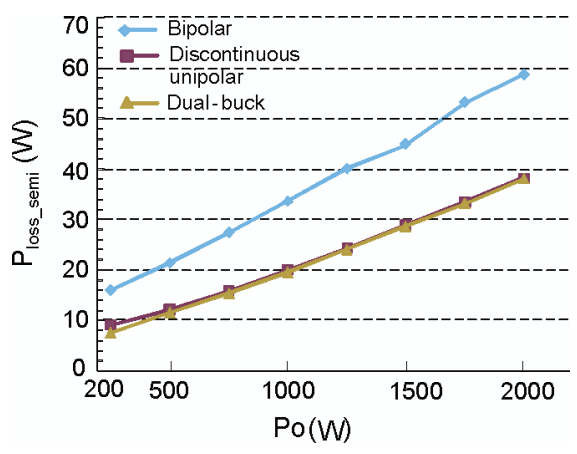

Fig. 5. Power losses of the inverter power components under the three modulation methods when the current ripple is $30 \%$

\section{Analysis on power losses in inductors}

The power losses of the inductor can be separated into core loss $\left(P_{\text {core }}\right)$ and copper loss $\left(P_{\text {copper }}\right)$. The core loss includes the hysteresis loss, the eddy current loss and the residual loss in the magnetic material [20]. The copper loss includes the dc-resistance loss and the acresistance loss, caused by the fundamental frequency current and the switching frequency ripple current in the winding respectively. The power loss of inductor varies with the type of core material, the type of winding, and the switching frequency of the operation. 


\section{A. Copper losses calculation}

The skin and proximity effects contribute to the copper loss in the winding [21]. The acresistance of an inductor, $R_{a c}$, can be described as:

$$
\begin{gathered}
Q=\frac{0.843 d \sqrt{\frac{d}{s}}}{\chi}, \\
R_{a c}=F_{R} R_{d c},
\end{gathered}
$$

where $d$ is the diameter of wire, $s$ is the center distance of neighboring wire, $\chi$ is the skin depth, $Q$ is the relative height of the equivalent quadrate conductor, $R_{\mathrm{dc}}$ is the dc-resistance of the winding wire. According to the value of $Q$ and the total number of winding layers, the ratio of ac-resistance versus dc-resistance $\left(F_{\mathrm{R}}\right)$ can be obtained by the Dowell curve [22]. The copper loss of the inductor can be calculated as:

$$
P_{\text {copper }}=I_{f} R_{d c}^{2}+I_{a c} R_{a c}^{2},
$$

where $I_{\mathrm{f}}$ is the RMS value of the fundamental frequency current component, $I_{\mathrm{ac}}$ is the RMS value of the ac-ripple current component.

\section{B. Core losses calculation}

When proper magnetic material is selected for the high-frequency operation, the core loss can be calculated with the sufficient accuracy using the Steinmetz equations supplied by the manufacturer's datasheet using the following equations,

$$
\begin{gathered}
P_{\text {core }}=K_{D}\left(B_{a c}^{2.00} f_{s}^{1.60} V_{e}\right), \\
K_{D}=\left[\frac{2}{D(1-D) \pi^{2}}\right]^{(1.6-1)},
\end{gathered}
$$

where $B_{\text {ac }}$ is the flux density, in Tesla; $V_{\mathrm{e}}$ is the magnetic core volume, in $\mathrm{cm}^{3}$ and $K_{\mathrm{D}}$ is the loss ratio between the sine wave excitation and the square wave excitation [23].

From Table 1, it can be seen that the inverter-side inductors of LLCL- and LCL-filter are the same due to the same current ripple ratio. However, the grid-side inverter of LLCL-filter is much smaller than that of LCL-filter, which causes the main power loss difference between these two filters. The power loss curves of the LLCL-filter and the LCL-filter under the three modulation schemes are drawn in Figures 6-8 respectively. It can be seen the difference of power loss is being enlarged with the increased output power, which is mainly due to the increased copper loss. Further, the modulation method also affects the power loss difference through the current ripple of the grid side inductor. But their characteristics as function of the output power are the similar. 

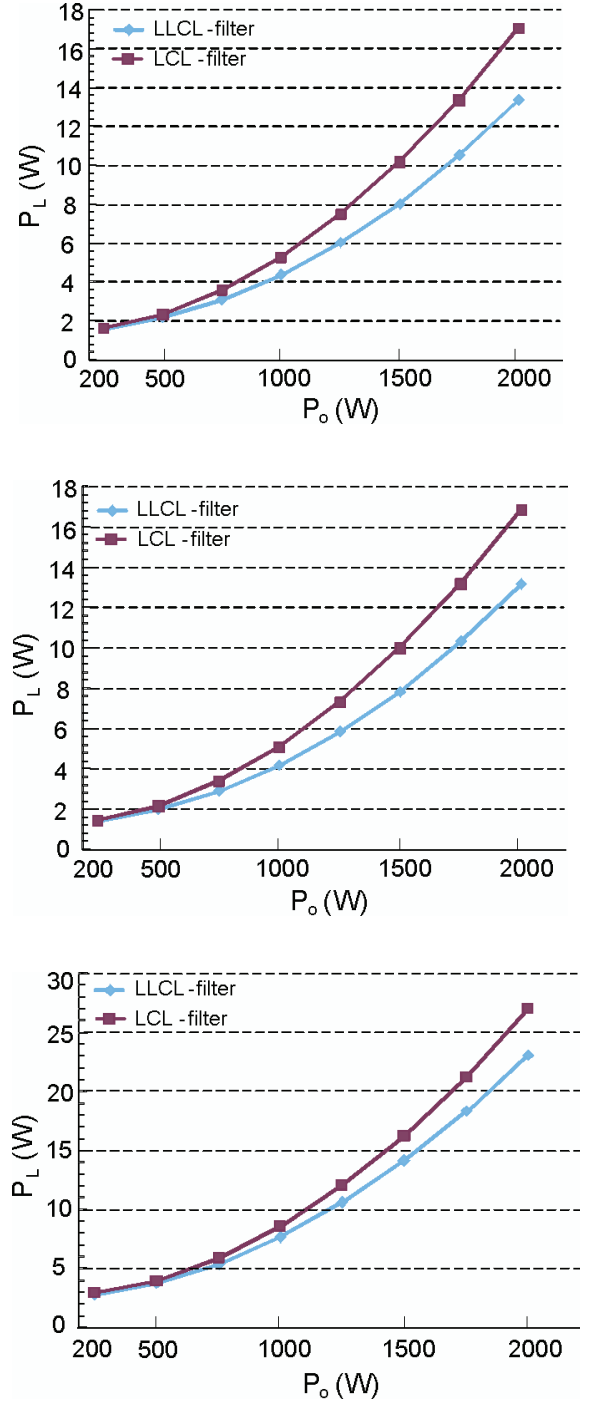

Fig. 6. Total power losses of the LLCL-filter and the LCL-filter under the discontinuous unipolar modulation

Fig. 7. Total power losses of the LLCL-filter and the LCL-filter under the dual-buck modulation

Fig. 8. Total power losses of the LLCL-filter and the LCL-filter under the bipolar modulation

\section{Efficiency comparison}

\section{A. Calculation results}

The calculated looses of the inverter are based on the designed variables shown in Table 1 and Table 2 .

The calculated efficiencies of the inverter under the three modulation methods of the LLCLfilter and the LCL-filter based grid-tied inverters are shown in Figures 9-11 under the conditions described in Table 2. 
a)

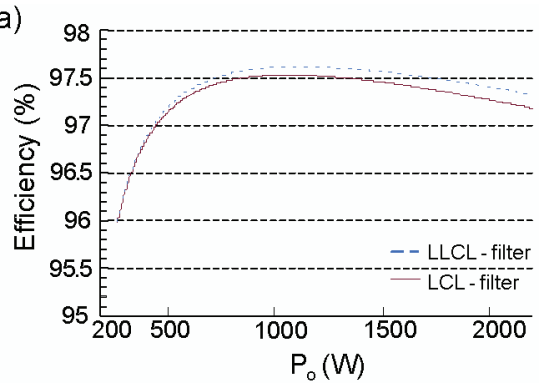

b)

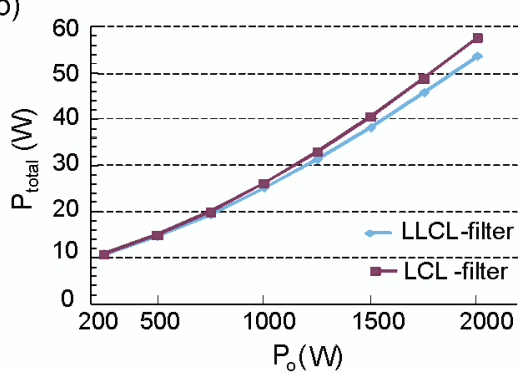

Fig. 9. Calculation of LLCL- and LCL-filter based single-phase grid-tied inverters using discontinuous unipolar modulation: a) efficiencies, b) total power losses
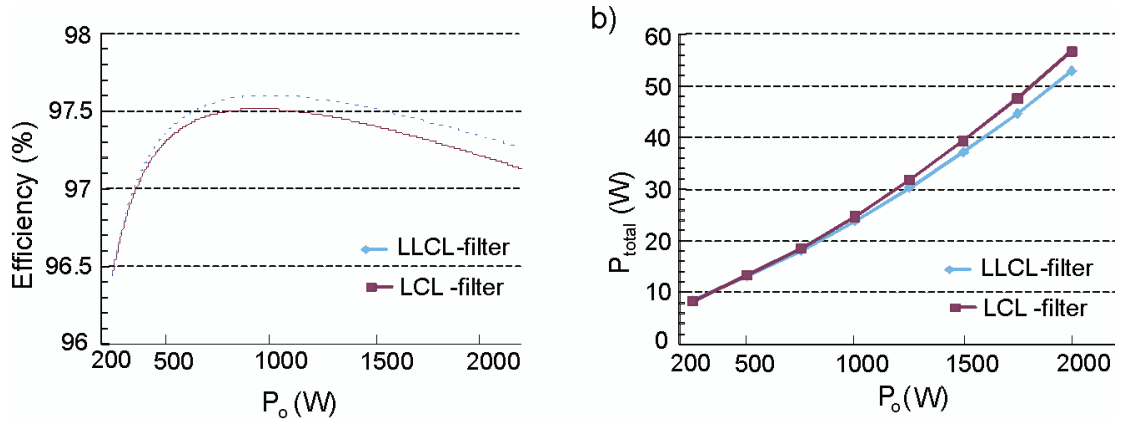

Fig. 10. Calculation of LLCL- and LCL-filter based single-phase grid-tied inverters using the dual-buck modulation: a) efficiencies, b) total power losses

a)

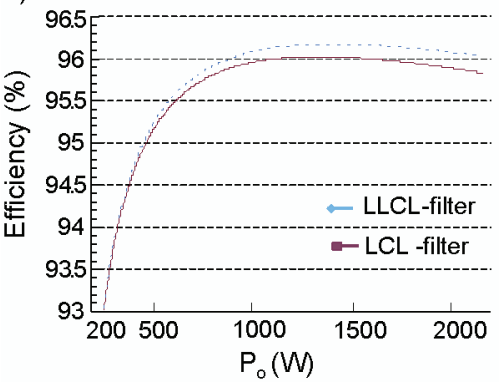

b)

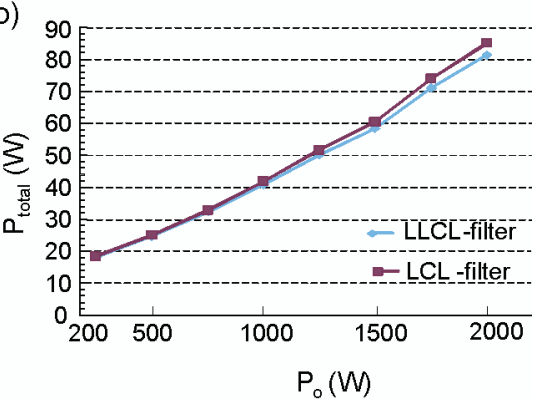

Fig. 11. Calculation of LLCL- and LCL-filter based single-phase grid-tied inverters using the bipolar modulation: a) efficiencies, b) total power losses

It can be seen that the modulation obviously influences the efficiency and the LLCL-filter based grid-tied inverter has higher efficiency than the LCL-filter based, especially when the output power is high. The efficiency of the bipolar modulation is the lowest of three methods, due to the high frequency operation of the four switches in the converter. 


\section{B. Experimental results}

In order to verify the theoretical analysis on the LLCL- and LCL-filter based systems under the different modulation condition, a $2 \mathrm{~kW}$ prototype (as shown in Figure12 a)) with the DSP (TMS320LF2808) controller is designed and constructed. The parameters of the filters are listed in Table 1 under the given that $f_{\mathrm{s}}=20 \mathrm{kHz}, U_{\mathrm{dc}}=350 \mathrm{~V}, U_{\mathrm{g}}=220 \mathrm{~V} / 50 \mathrm{~Hz}$, $P_{\text {rated }}=2 \mathrm{~kW}$ and using a dead time $t_{\mathrm{d}}=2 \mu \mathrm{s}$. A programmable AC voltage source (Chroma 6530 ) is used to emulate the grid voltage and a WT1600 is adopted to measure the efficiency and the THD $\%$ of currents injected into the grid.

Figure $12 \mathrm{~b}$ ) shows $L_{f}$ of the LLCL-filter and the grid inductors of the LLCL-filter and the LCL-filter respectively. And it can be seen the total volume and weight of the resonant inductor $L_{f}$ plug the grid-side inductor of LLCL-filter are much smaller than those of the gridside inductor of LCL-filter.

a)

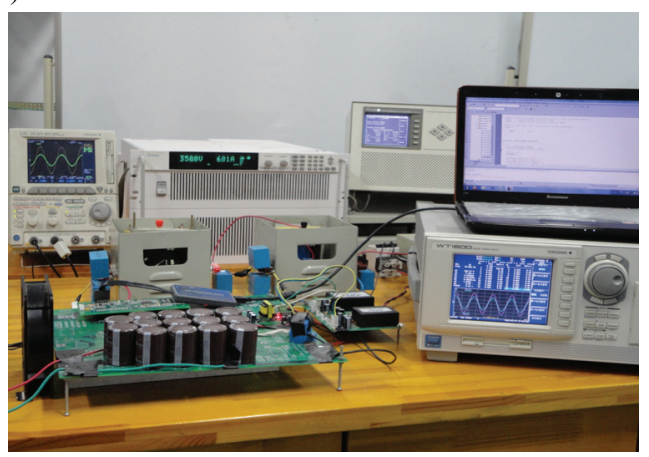

b)

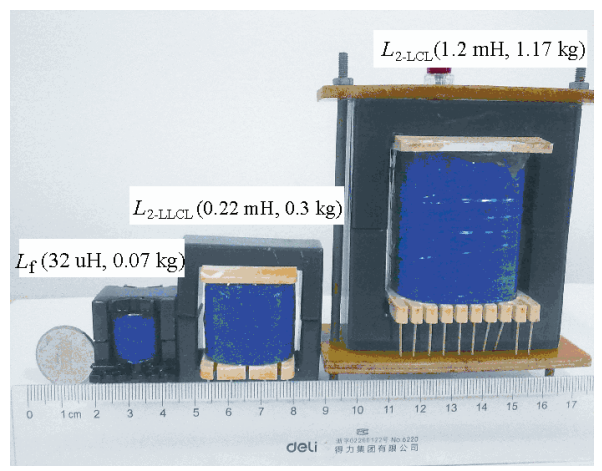

Fig. 12. Photo of experimental prototype and inductors: a) $2 \mathrm{~kW}$ prototype, b) inductors

a)

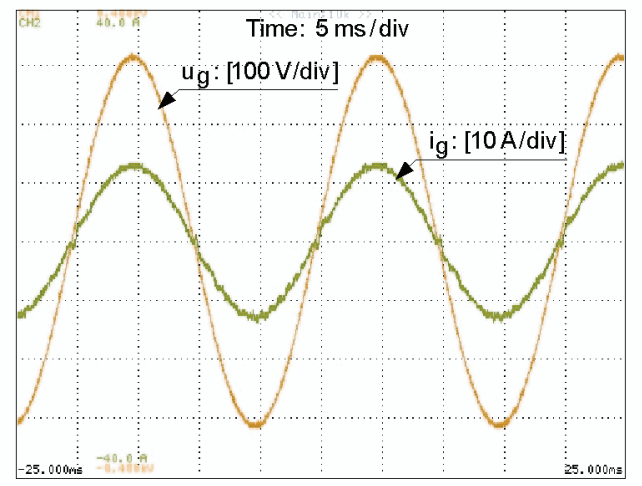

b)

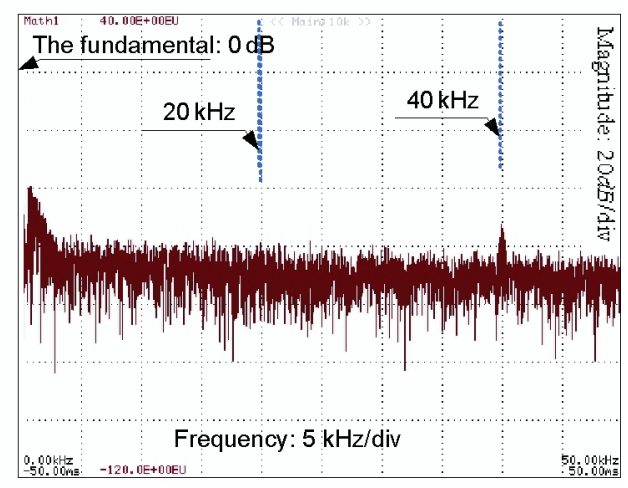

Fig. 13. Experimental results of the LLCL-filter based inverter system using the discontinuous unipolar modulation: a) grid voltage and grid-side current waveforms, b) power spectrum of grid-side current 
a)

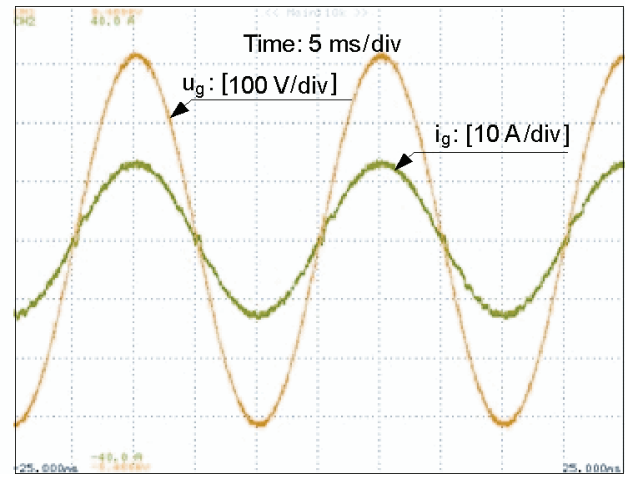

b)

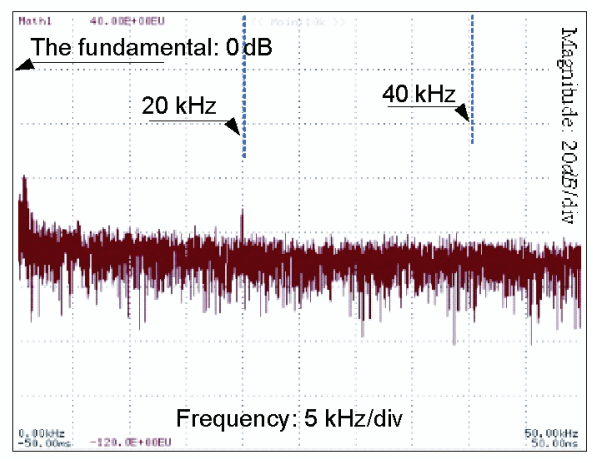

Fig. 14. Experimental results of the LCL-filter based inverter system using the discontinuous unipolar modulation: a) grid voltage and grid-side current waveforms b) power spectrum of grid-side current

a)

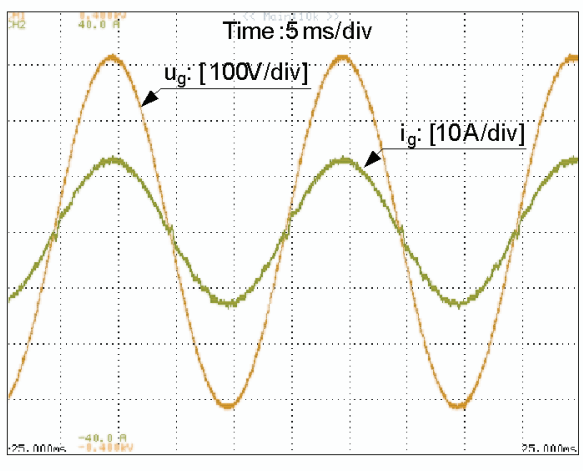

b)

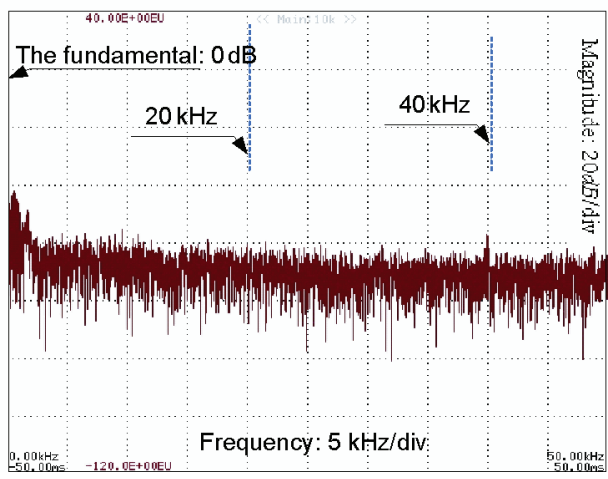

Fig. 15. Experimental results of the LLCL-filter based inverter system using the dual-buck modulation: a) grid voltage and grid-side current waveforms, b) power spectrum of grid-side current

a)

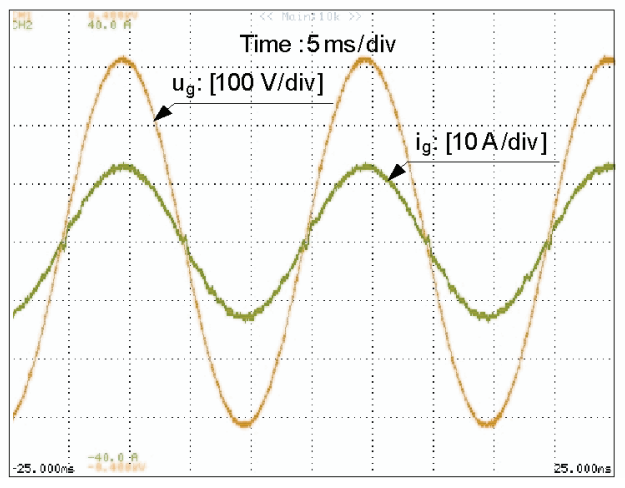

b)

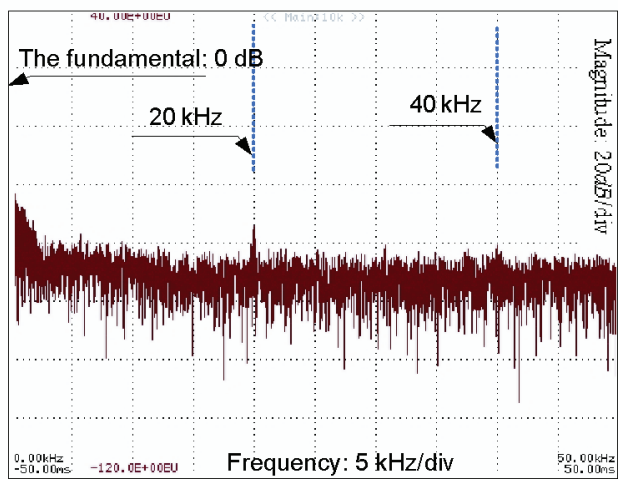

Fig. 16. Experimental results of the LCL-filter based inverter system using the dual-buck modulation: a) grid voltage and grid-side current waveforms, b) power spectrum of grid-side current 
a)

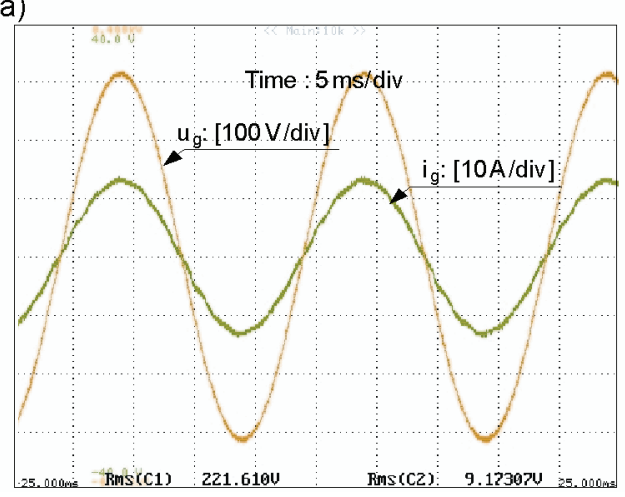

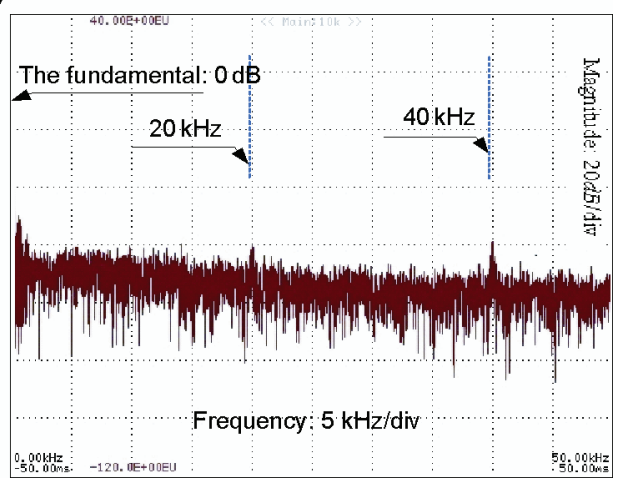

Fig. 17. Experimental results of the LLCL-filter based inverter system using the bipolar modulation: a) Grid voltage and grid-side current waveforms, b) power spectrum of grid-side currentg

a)

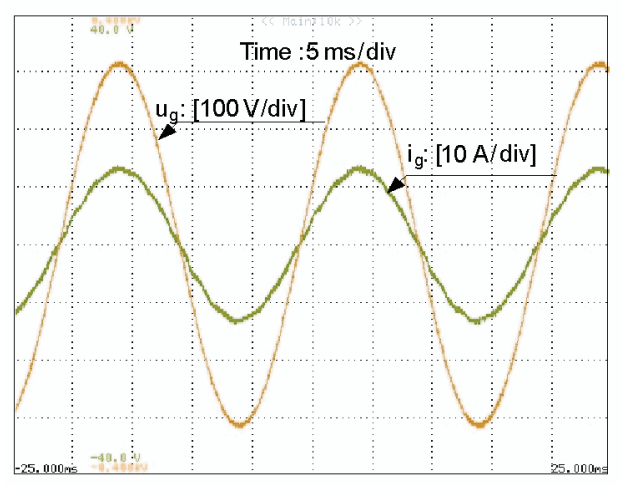

b)

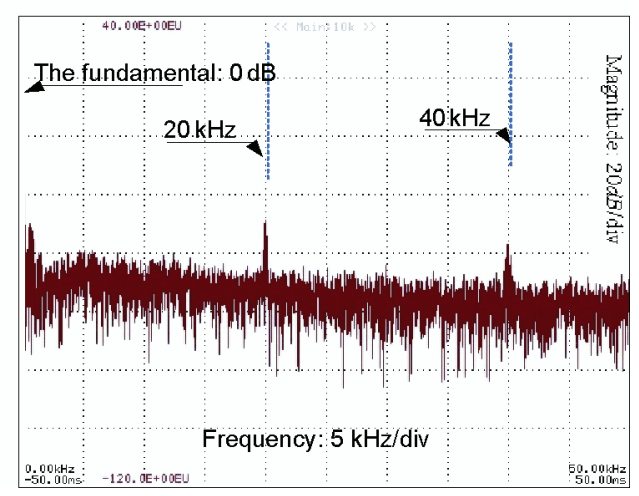

Fig. 18. Experimental results of the LCL-filter based inverter system using the bipolar modulation: a) grid voltage and grid-side current waveforms, b) power spectrum of grid-side current

Table 3. The measured thd (\%) of the grid-side currents

\begin{tabular}{c|c|c|c|c|c|c}
\hline $\begin{array}{c}\text { Modulation } \\
\text { method }\end{array}$ & \multicolumn{2}{|c|}{$\begin{array}{c}\text { Dual-buck modulation } \\
\text { [\%] }\end{array}$} & \multicolumn{2}{c|}{$\begin{array}{c}\text { Discontinuous unipolar } \\
\text { modulation [\%] }\end{array}$} & \multicolumn{2}{c}{$\begin{array}{c}\text { Bipolar modulation } \\
\text { [\%] }\end{array}$} \\
\hline Power (W) & LCL-filter & LLCL-filter & LCL-filter & LLCL-filter & LCL-filter & LLCL-filter \\
\hline 250 & 6 & 4.63 & 5.26 & 5.15 & 7.10 & 6.8 \\
\hline 500 & 3.59 & 3.26 & 3.65 & 3.75 & 5.11 & 4.50 \\
\hline 750 & 2.57 & 2.44 & 2.56 & 2.50 & 3.70 & 3.51 \\
\hline 1000 & 2.29 & 2.13 & 2.25 & 2.20 & 2.59 & 2.55 \\
\hline 1250 & 2.07 & 2.03 & 2.12 & 2.08 & 2.37 & 2.34 \\
\hline 1500 & 1.97 & 1.85 & 2.01 & 1.96 & 2.15 & 2.10 \\
\hline 1750 & 1.81 & 1.71 & 1.90 & 1.81 & 1.97 & 1.90 \\
\hline 2000 & 1.71 & 1.63 & 1.81 & 1.70 & 1.87 & 1.82 \\
\hline
\end{tabular}


Figures 13-18 show the measured grid currents and their power spectrums under the conditions described in Table 2. The attenuation of the dominant switching harmonic currents are $-53 \mathrm{db},-54 \mathrm{db},-56 \mathrm{db},-54 \mathrm{db},-58 \mathrm{db}$ and $-50 \mathrm{db}$ respectively, which means all expect for the last case can meet the requirement specified by the IEEE 519-1992. The main reason is that when the bipolar modulation is adopted for the single phase grid-tied inverter, the harmonic currents around the switching frequency are more abundant than those of the inverter using the dual-buck modulation or the discontinuous unipolar modulation.

The measured THD (\%) of the grid side-currents are listed in Table 3. It can be seen that the THD (\%) of the LLCL-filter based system is lower than that of the LCL-filter based system, no matter which modulation method is adopted mainly due to a higher control bandwidth can be achieved.

Fig. 19. Measured efficiencies of the LLCL-filter and the LCL-filter based single-phase grid-tied inverters using the discontinuous unipolar modulation

Fig. 20. Measured efficiencies of the LLCL-filter and the LCL-filter based single-phase grid-tied inverters using the dual-buck modulation
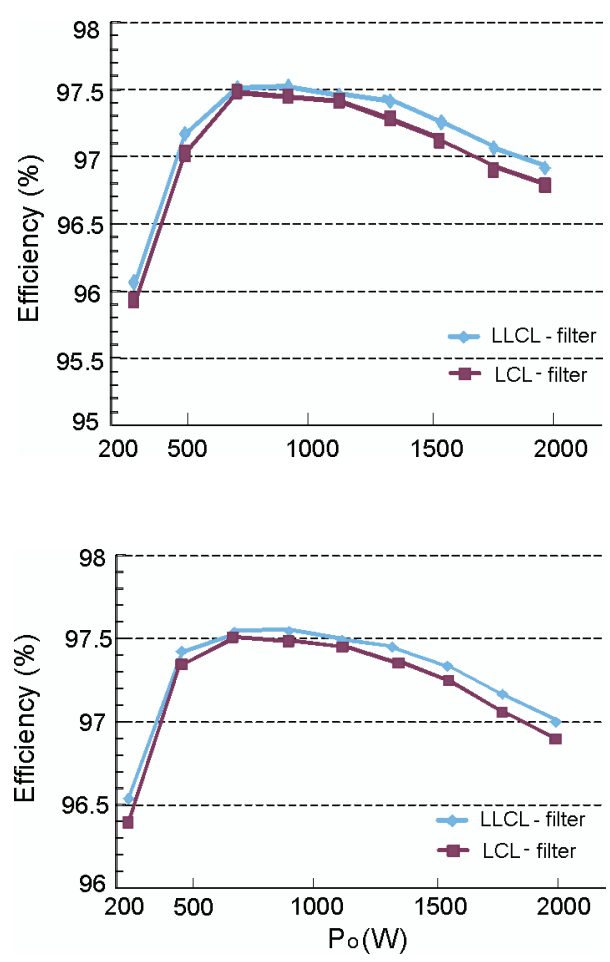

Fig. 21. Measured efficiencies of the LLCL-filter and the LCL-filter based single-phase grid-tied inverters using the bipolar modulation

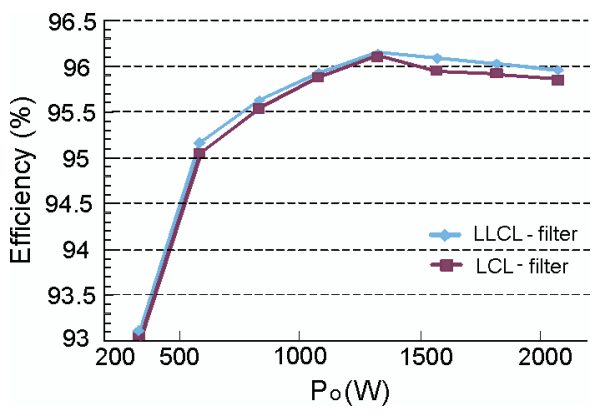


Figures 19-21 depict the measured experimental efficiencies of the inverter using the three modulation methods respectively. It can be seen that they have the similar trends as the calculated ones, although there are some difference in low output power states, which mainly are caused by the extra stray power losses. It can be also seen that the modulation strategy affects the efficiency, especially when the inverter works in the low power state. The efficiency of the LLCL-filter based inverter system is a slightly higher than the LCL-filter based inverter system.

\section{Conclusions}

In industrial applications, an LLCL-filter can decrease the total inductance, the cost and the weight significantly, compared to an LCL-filter. In this paper, an efficiency comparison of the LLCL-filter based power system and the LCL-filter based power system are carried out using the three different modulation methods. It can be seen that:

1) The power losses in the power components of the LLCL- and the LCL-filter based singlephase grid-tied inverter systems are similar, only if the current ripples are the same.

2) The bipolar modulation causes more power losses than the unipolar modulation and the dual-buck modulation significantly.

3) The efficiency for the dual-buck modulation is slightly higher than the discontinuous unipolar modulation, especially in the low power operation.

4) In a single-phase grid-tied VSI, no matter which modulation method is adopted, the efficiency of the LLCL-filter based system is higher than the LCL-filter based system due to its smaller grid-side inductance.

5) The THD of the grid-side current of the LLCL-filter based grid-tied inverter can be lower than that of the LCL-filter based due to a higher control bandwidth can be achieved.

A $2 \mathrm{~kW}$ single-phase grid-tied VSI prototype has been implemented to verify the theoretical efficiency analysis on the LLCL-filter and the LCL-filter. It can be seen that experimental results match the theoretical analysis quite well.

\section{Acknowledgment}

This work was partially supported partly by the Project from Shanghai Municipal Education Commission under Award13ZZ125 and the Project of Shanghai Natural Science Foundation under Award 12ZR1412400.

\section{References}

[1] Blaabjerg F., Ma K., Liserre M., Power Electronics Converters for Wind Turbine. IEEE Trans. Ind. Appl. 48(2): 708-719 (2012).

[2] IEEE1547.2-2008, IEEE Application Guide for IEEE Std. 1547, IEEE Standard for Interconnecting Distributed Resources with Electric Power Systems (2008).

[3] IEEE 519-1992, IEEE Recommended Practices and Requirements for Harmonic Control in Electrical Power Systems (1992). 
[4] Wu W., He Y., Blaabjerg F., An LLCL Power Filter for Single-Phase Grid-Tied Inverter. IEEE Trans. Power Electron. 27(2): 782-789 (2012).

[5] Wu W., He Y., Tang T., Blaabjerg F., A New Design Method for the Passive Damped LCL- and LLCL-Filter Based Single-Phase Grid-tied Inverter. IEEE Trans. Ind. Electron. 60(10): 4339-4350 (2013).

[6] Wu W., Sun Y., Huang M. et al., A Robust Passive Damping Method for LLCL Filter Based GridTied Inverters to Minimize the Effect of Grid Harmonic Voltages. IEEE Trans. Power Electron. (2013) (in press).

[7] Wu W., Sun Y., Lin Z., et al., A Modified LLCL-filter with the Reduced Conducted EMI Noise. IEEE Trans. Power Electron. (2013) (in press).

[8] Wu T.F., Chang C.H., Lin L.C., Kuo C.L., Power Loss Comparison of Single- and Two-Stage GridConnected Photovoltaic Systems. IEEE Trans. Energy Conversion 26(2): 707-715 (2011).

[9] Pires V.F., Martins J.F., Chen H., A modular multilevel power converter system for photovoltaic applications. Proc. POWERENG, Malaga, Spain, pp. 1-5 (2011).

[10] Ji B., Wang J., Zhao J., High-Efficiency Single-Phase Transformer less PV H6 Inverter With Hybrid Modulation Method. IEEE Trans. Ind. Electron. 60(5): 2104-2115 (2013).

[11] Wu Y., Shafi M.A., Knight A.M., McMahon R.A., Comparison of the Effects of Continuous and Discontinuous PWM Schemes on Power Losses of Voltage-Sourced Inverters for Induction Motor Drives. IEEE Trans. Power Electron. 26(1): 182-191(2011).

[12] Yao Z., Xiao L., Control of Single-Phase Grid-Connected Inverters with Nonlinear Loads. IEEE Trans. Ind. Electron. 60(4): 1384-1389 (2013).

[13] Zhang X., Gong C., Dual-Buck Half-Bridge Voltage Balancer. IEEE Trans. Ind. Electron., 60(8): 3157-3164 (2013).

[14] Holmes D.G., Lipo T.A., Pulse Width Modulation for Power Converters: Principles and Practice. Hoboken, NJ: Wiley-IEEE Press (2003).

[15] Liserre M., Blaabjerg F., Hansen S., Design and control of an LCL-filter-based three-phase active rectifier. IEEE Trans. Ind. Appl. 41(5): 1281-1291 (2005).

[16] Vazquez A., Rodriguez A., Fernandez M., et al., On the Use of Front-End Cascode Rectifiers Based on Normally-on SiC JFET and Si MOSFET. IEEE Trans. Power Electron. (2014) (in press).

[17] Ebrahimi J., Babaei J., Gharehpetian G.B., A New Multilevel Converter Topology with Reduced Number of Power Electronic Components. IEEE Trans. Ind. Electron. 59(2): 655-667 (2012).

[18] Wu W., Wang X., Geng P., Efficiency analysis for three phase grid-tied PV inverter. Proc. ICIT2008, Chengdu, China, pp. 1-5 (2008).

[19] Geng P., Wu W., Huang M., Blaabjerg F., Efficiency analysis on a two-level three-phase quasi-softswitching inverter. Proc. APEC 2013, Long Beach, CA, USA, pp. 1206-1212 (2013).

[20] Musavi F., Eberle W., Dunford W.G., A High-Performance Single-Phase Bridgeless Interleaved PFC Converter for Plug-in Hybrid Electric Vehicle Battery Chargers. IEEE Trans. Ind. Appl. 47(3): 1833-1843 (2011).

[21] Hamalainen H., Pyrhonen J., NergJ., TalvitieJ., AC Resistance Factor of Litz-Wire Windings Used in Low-Voltage High-Power Generators. IEEE Trans. Ind. Electron. 61(2): 693-700 (2014).

[22] Dowell P.L., Effects of eddy currents in transformer windings. IEE Proceeding 113(8): 1387-1394 (1966).

[23] Matsumori H., Shimizu T., Takano K., Ishii H., Iron loss calculation of AC filter inductor for three phase PWM inverter. Proc. ECCE 2012, Raleigh, NC, pp. 3271-3278 (2012). 